\title{
Quantitative allometry of gamete production by Mercenaria mercenaria into old age
}

\author{
C. H. Peterson \\ University of North Carolina at Chapel Hill, Institute of Marine Sciences, Morehead City, North Carolina 28557, USA
}

\begin{abstract}
Among 67 hard clams Mercenaria mercenaria collected during spawning on 4 June 1982 from Core Sound, North Carolina (USA), gonadal mass increased significantly with body size (shell length and internal volume). Clam age did not explain a significant amount of the residual variance in the linear regression of log gonadal mass on log shell length. Because this collection contained 11 individuals over 24 yr of age, including the oldest $M$. mercenaria ever reported at 41 and $46 \mathrm{yr}$, these results imply that gamete production in $M$. mercenaria continues into old age at a quantitative level predicted simply by the power curve relating gonadal mass to body size. There was no suggestion of even partial reproductive senility in gamete production at old age. Exponents in the 2 power curves relating gonadal mass to shell length (3.1) and shell volume (1.1) did not differ significantly from those expected under isometric growth of gonadal mass.
\end{abstract}

Knowledge of how reproductive output in any organism changes with age is critical to completing the agespecific fecundity function $\left(m_{x}\right)$ of its life table and necessary for a better understanding of the general incidence and character of reproductive senility among different groups of species. In marine invertebrates, reproductive output (gamete production) generally increases as a function of increasing body size (reviewed by Spight \& Emlen 1976, Hughes \& Roberts $1980)$. In such studies of the allometry of gamete production with changing body size, organism age is usually an unknown factor. Because individual growth rate declines rapidly with increasing age and quickly approaches zero in solitary marine invertebrates (e.g. Hallam 1967) and because the oldest age classes usually represent a small fraction of any population, the existence of reproductive senility at some particular age would rarely be detectable in such allometric studies. Average gamete production would still increase monotonically with body size. Although the presence of reproductive senility might be detected by a significant increase in the variance in gamete production at the largest size classes (Vahl 1985), an analysis that incorporates age information directly is a more direct and preferable means of testing for reproductive senility.

Many bivalve molluscs can be aged by counting growth bands incorporated into their shells (Rhoads \& Lutz 1980), thus providing one group of marine invertebrates amenable to a ready test of how age affects reproductive output. I suggested previously (Peterson 1983) that in addition to looking for absolute reproductive senility (zero reproductive output after some age) one might also test for quantitative (= partial) reproductive senility, defined as the degree to which reproductive output after some age falls short of that expected from the curve relating reproductive output to body size alone among all adults younger than that initial age of the onset of partial senility. The hard clam Mercenaria mercenaria (L.) in 2 collections from Back Sound, North Carolina, exhibited no evidence of even partial reproductive senility (Peterson 1983), but Vahl (1985) has since discovered a substantial decline in gamete production of the Iceland scallop Chlamys islandica in the oldest age classes. Because my previous test for quantitative reproductive senility in $M$. mercenaria only included individuals ranging up to age 19 (Peterson 1983) despite the known occurrence of substantially older clams nearby (Peterson et al. 1983), I extend my tests of how age affects gamete production in $M$. mercenaria by analyzing here a collection that includes far older clams ranging up to age 46.

Methods. To test how gamete production varies with body size and age among relatively old Mercenaria mercenaria, I collected M. mercenaria on June 4, 1982 from the Johnson Creek area of Core Sound near Cape Lookout, North Carolina (USA). Johnson Creek (described in detail and charted in Peterson et al. 1983) is a shallow tidal creek that drains Spartina alterniflora marshes bordering the barrier island of Core Banks. The collection area was in shallow 0.1 to $0.5 \mathrm{~m}$ water 
coverage at low tide) subtidal waters and was characterized by bottom surface $(0$ to $5 \mathrm{~cm})$ sediments comprised of about half fine sands and half silts and clays by weight. Clams were gathered by both rake and suction dredge with no attempt at preserving natural size-frequency distributions. I chose the early June sampling date to fall after the reported season of gametogenesis but before most gamete release (Porter 1964) to enable me to use the dry mass of all gonadal material as a relative measure of size-specific fecundity (one possible measure of reproductive effort: Vahl 1981).

All 67 clams collected were transported to the laboratory in dry buckets and then frozen at $-8^{\circ} \mathrm{C}$ for 1 to $5 \mathrm{wk}$ before dissection. Clams were removed from the freezer in small groups and measured individually to the nearest $0.1 \mathrm{~mm}$ with vernier calipers in each of 3 perpendicular, linear dimensions (length, height and thickness). After thawing, all dissections were carried out by the same person over a $5 \mathrm{wk}$ period to achieve uniformity in a somewhat subjective process. For each clam, gonadal tissues were scraped away from the remaining soft somatic tissues. Each fraction was placed into a separate aluminum weighing dish and dried to constant weight $(3$ to $4 \mathrm{~d})$ at $65^{\circ} \mathrm{C}$. After dissection, 1 valve from each clam was sectioned and aged by the process described and tested for North Carolina in Peterson et al. (1983).

This procedure produced 3 necessary pieces of information on each clam: its size, age, and gonadal mass near the beginning of the spawning season. To test for possible quantitative (partial) reproductive senility, I performed single linear regressions on $\log _{10}$-transformed variables to determine which independent variable, size or age, explained more of the variation in gonadal mass and multiple linear regressions on $\log _{10^{-}}$ transformed variables to test whether age explained any significant proportion of the residual variation around the regression of gonadal mass on clam shell size (length). The use of a single linear regression between 2 log-transformed variables is equivalent to fitting a power curve: the exponent in the power curve becomes the regression coefficient (slope) in the linear regression. The handling, dissection, and analytical procedures are identical to those used in Peterson (1983) and permit a contrast between the new (4 June 1982) results incorporating older clams from Johnson Creek and the previous results from 22 to 29 May 1980 and 3 to 11 June 1981 collections from nearby Back Sound, North Carolina.

Results. The 1982 collection from Johnson Creek contained relatively old Mercenaria mercenaria. Eleven of the 67 clams were 25 yr of age or older, while the 2 oldest were 41 and 46 . The single linear regressions between the double log-transformed variables (Fig. 1)

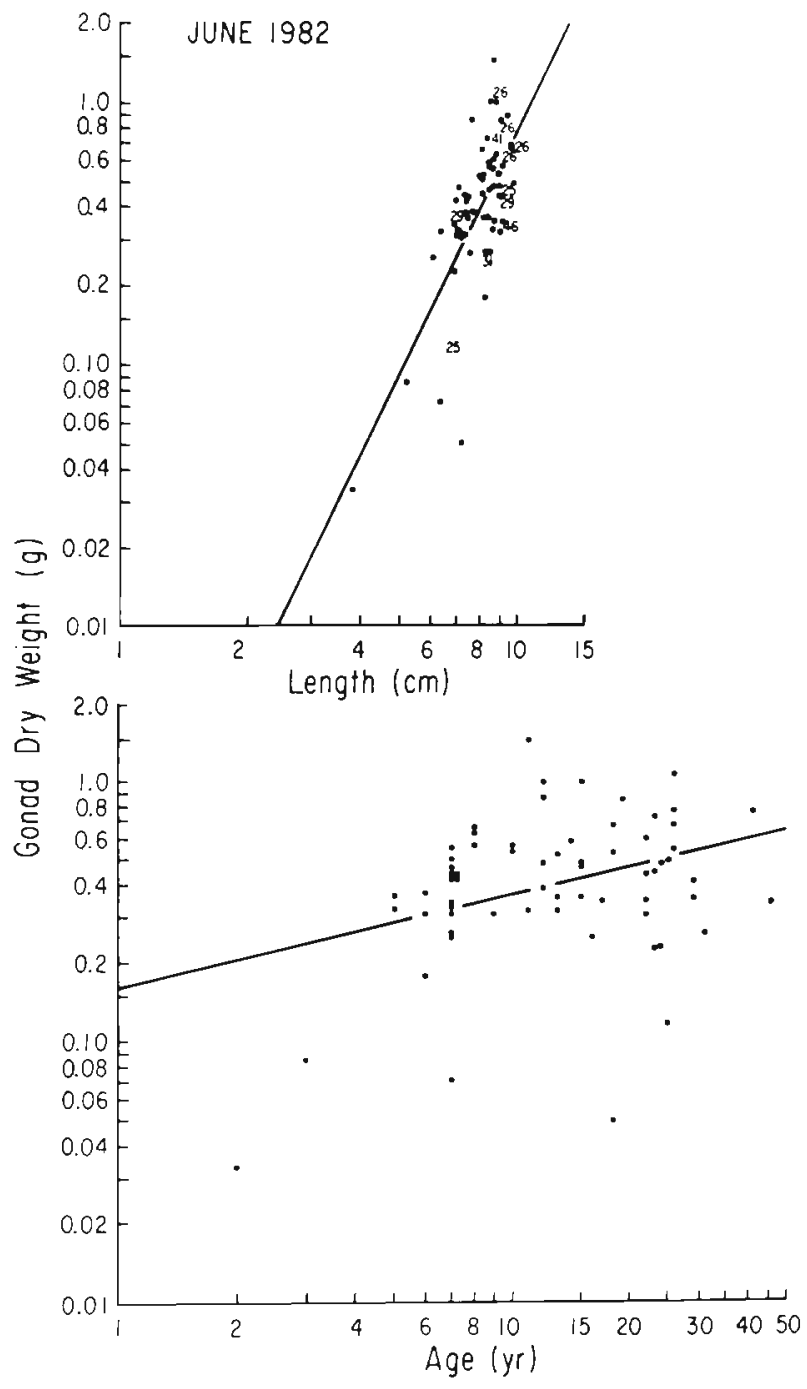

Fig. 1. Mercenaria mercenaria. Gonadal mass on 4 June 1982 as a function of shell length (top) and age (bottom), as estimated by growth lines. Regression equations and fits given in Table 1. In the top graph, ages of all clams $25 \mathrm{yr}$ old or older are plotted as the data points to illustrate the lack of effect of old age on the fit

revealed that clam length $\left(\mathrm{r}^{2}=0.53\right)$ was a better predictor of gonadal mass than clam age $\left(\mathrm{r}^{2}=0.11\right)$. In the multiple linear regression among log-transformed variables (Table 1), clam age did not contribute significantly to explaining variance in gonadal mass although length was highly significant $(p<0.001)$. The multiple linear regression using length and age as independent variables was able to explain only $1 \%$ more of the variance in gonadal mass (54\% vs $53 \%$ : Table 1) than could be explained by clam length alone. Age also did not explain a significant $(a=0.05)$ proportion of the residual variance around the single linear regression of gonadal mass on clam length. To illustrate how old age failed to contribute significantly to the shape of the 
Table 1. Mercenaria mercenaria. Outcomes of single and multiple linear regressions among $\log _{10}$-transformed variables of dry gonadal mass $(G)$ in $g$ on shell length $(\mathrm{L})$ in $\mathrm{cm}$ clam age (A) in yr and internal shell volume (V) in $\mathrm{cm}^{3}$ for 1982 collection from Johnson Creek. $95 \%$ Cl for each regression coefficient is given in parentheses. Sample size is 67 individuals for all regressions

\begin{tabular}{|c|c|c|c|}
\hline \multicolumn{3}{|r|}{ Regression equation } & $r^{2}$ \\
\hline (1) & $\log G=$ & $-3.26+3.14( \pm 0.73) \log L \cdots$ & $0.53^{\mathrm{d}}$ \\
\hline (2) & $\log G=$ & $-0.79+0.35( \pm 0.25) \log A \cdots$ & 0.11 \\
\hline (3) & $\log G=$ & $\begin{aligned}-3.44 & +3.53( \pm 0.91) \log L^{\cdots} \\
& -0.16( \pm 0.22) \log A^{N S}\end{aligned}$ & 0.54 \\
\hline (4) & $\log G=$ & $-2.35+1.12( \pm 0.28) \log V \cdots$ & 0.50 \\
\hline \multicolumn{4}{|c|}{$\begin{array}{l}\cdots p<0.01 ; \quad \cdots p<0.001 ; \quad N S: p>0.05 \\
\text { a Age did not explain a significant proportion of residual } \\
\text { variance in the single linear regression of } \log G \text { on } \log L\end{array}$} \\
\hline
\end{tabular}

relation between clam size and gonadal mass, ages of all clams older than 24 yr of age are plotted instead of points in their appropriate positions around the regression line of gonadal mass on clam length (Fig. 1). Of these 11 oldest clams in the collection, 5 fell above the line and 6 below, demonstrating that quantitative gamete production for the oldest $M$. mercenaria did not fall short of what could be expected on the basis of shell size alone.

In this 1982 collection of Mercenaria mercenaria from Johnson Creek, the regression coefficient in the linear regression of log gonadal mass on log shell length was not significantly different from 3.0 (Table 1 ): the $95 \%$ confidence interval was 2.41 to 3.87. A regression coefficient of 3 implies isometric change in gonadal mass with increasing shell length. To examine further the potential allometry of fecundity, I utilized all 3 linear measurements to calculate estimated internal volume (V) of each individual clam, using the regression equation $(\mathrm{V}=1.64+0.22$ $\mathrm{L} \times \mathrm{H} \times \mathrm{T}_{;} \mathrm{n}=20, \mathrm{r}^{2}=0.997$ ) in Peterson (1983). In a linear regression, log shell volume explained $(p<0.001)$ about the same proportion of variance in log gonadal mass as did log shell length (Table 1). The regression coefficient in the regression of log gonadal mass on log internal shell volume was not significantly different from unity (95\% CI of 0.84 to 1.40 ), again implying isometric change in gonadal mass with increasing shell size.

My inability to show significant departure from isometric reproductive output with changing shell size in the 1982 Johnson Creek collection of Mercenaria mercenaria contrasts greatly with the results of identical regression analyses done on the 1980 and 1981 collections from Back Sound (Table 2). In both previous collections, gonadal mass increased allometrically
Table 2. Mercenaria mercenaria. The contrasting allometry of gamete production as a function of body size in 3 separate collections. Presented are the regression coefficients ( $\pm 95 \%$ CI) from the linear regressions of log gonadal mass (G) on log shell length (L) and on log internal shell volume (V). Data for 1980 and 1981 collections come from Peterson (1983). The first set of regressions (a) was performed on the complete data sets, whereas the second set (b) was performed on only those clams $>6 \mathrm{~cm}$ to remove the possible influence of changing sizefrequency distributions among collections. $n=$ numbers of clams entering into the analysis

\begin{tabular}{|c|c|c|c|c|}
\hline & \multirow[t]{2}{*}{ Collection } & \multicolumn{2}{|c|}{$\begin{array}{l}\text { Regression coefficient } \\
\text { of } \log G \text { on: }\end{array}$} & \multirow[b]{2}{*}{$\mathrm{n}$} \\
\hline & & $\log \mathrm{L}$ & $\log V$ & \\
\hline \multirow[t]{4}{*}{ (a) } & Complete data sets & & & \\
\hline & 1980 Back Sound & $4.07( \pm 0.51)$ & $1.80( \pm 0.21)$ & 62 \\
\hline & 1981 Back Sound & $4.09( \pm 0.50)$ & $1.59( \pm 0.19)$ & 108 \\
\hline & 1982 Johnson Creek & $3.14( \pm 0.73)$ & $1.12( \pm 0.28)$ & 67 \\
\hline \multicolumn{5}{|c|}{ (b) Reduced data sets (all clams } \\
\hline & 1980 Back Sound & $4.21( \pm 1.67)$ & $1.53( \pm 0.56)$ & 36 \\
\hline & 1981 Back Sound & $3.69( \pm 0.93)$ & $1.38( \pm 0.34)$ & 77 \\
\hline & 1982 Johnson Creek & $2.89( \pm 1.03)$ & $0.99( \pm 0.38)$ & 65 \\
\hline
\end{tabular}

at a significantly $(\alpha=0.05)$ more rapid rate than shell length cubed or internal shell volume. Partial F-tests from a dummy-variable multiple regression analysis on all 3 data sets simultaneously (methods in Kleinbaum \& Kupper 1978) revealed that the 3 regression lines of log gonadal mass on log shell length are not all parallel ( $\mathrm{p}<0.05$ ). The 1980 and 1981 lines are parallel and coincident, but the 1982 line differs significantly $(p<0.05)$ in slope in pairwise tests from each of the previous collections.

Because of the relative paucity of small clams in the 1982 collection (Fig. 1), I repeated this overall multiple regression analysis on subsets of each of the data sets (all clams $>6 \mathrm{~cm}$ in length) to free the between-collection contrasts from any influence of altering the range of variation in the independent variable (shell length). Removal of the smaller clams had the effect of lowering the regression coefficients in 5 of the 6 regressions (Table 2). Because of the reduced sample sizes, poorer regression fits, and smaller ranges in the independent variable, the dummy-variable multiple regression analysis on all 3 reduced data sets relating log gonadal mass to log shell length was unable to detect significant $(\alpha=0.05)$ differences in slopes (regression coefficients), although the lines were not coincident $(p<0.05)$. The large confidence intervals around the estimated slopes for each of the reduced data sets (Table 2) illustrate the low power of this test. Restriction of the data sets to include only the larger size classes of Mercenaria mercenaria failed to remove the 
large absolute differences between estimated slopes of the Back Sound and Johnson Creek data sets (Table 2).

Discussion. By extending my quantitative examination of gamete production in Mercenaria mercenaria to the extremely old clams of Johnson Creek, my original conclusion (Peterson 1983) about the lack of quantitative reproductive senility in this species is strengthened. Gonadal mass at the time of gamete release varies as a function of shell size, with even the oldest clams showing no consistent departure from the curve. The oldest individual in my previous 2 analyses of how reproductive output varies with size and age was only 19 (Peterson 1983). The new Johnson Creek collection contained 11 clams $25 \mathrm{yr}$ of age or older, including a 41- and a 46-yr-old. This 46 yr-old is the oldest $M$. mercenaria ever reported in the literature. I found no evidence here for absolute or even partial (quantitative) reproductive senility among the oldest $M$. mercenaria ever described.

The use of gonadal mass at spawning time to estimate relative fecundity in a seasonal spawner makes the assumptions that gamete viability does not vary with individual size or age and that all gametes are actually released such that gonadal mass after spawning declines to a constant (near-zero) value for individuals of all sizes and ages. These 2 assumptions were addressed briefly in my earlier study (Peterson 1983) by morphological examinations of gametes at spawning and of post-spawning gonads in clams of different ages. Now, evidence is available (Peterson \& Fegley 1986) on the relation between Mercenaria mercenaria shell size and gonadal mass for each month of the year in a North Carolina site. These data (Fig. 2) demonstrate that at least for that year (1982) and locality (Black Sound), gonadal mass declined to a constant, near-zero value for individuals of all sizes by December after all spawning was completed. Consequently, my use of gonadal mass at spawning as an index of relative fecundity (reproductive output) in $M$. mercenaria seems justifíable. Nevertheless, quantitative data on gamete viability as a function of age are still necessary to complete a test of whether reproductive senility occurs in this species.

No explicit theory exists to predict the relation for any given species between body size and fecundity. The exponent in the allometric (power) curve relating reproductive output to body size varies considerably even among similar species of marine invertebrates (Spight \& Emlen 1976). The general reduction in the power-curve exponents that accompanied the removal of smaller $(<6 \mathrm{~cm}$ ) Mercenaria mercenaria from my 3 North Carolina data sets (Table 2) suggests that fecundity (gonadal mass at spawning) may not be growing strictly according to a constant power of body size, but instead growing more rapidly than isometric at small

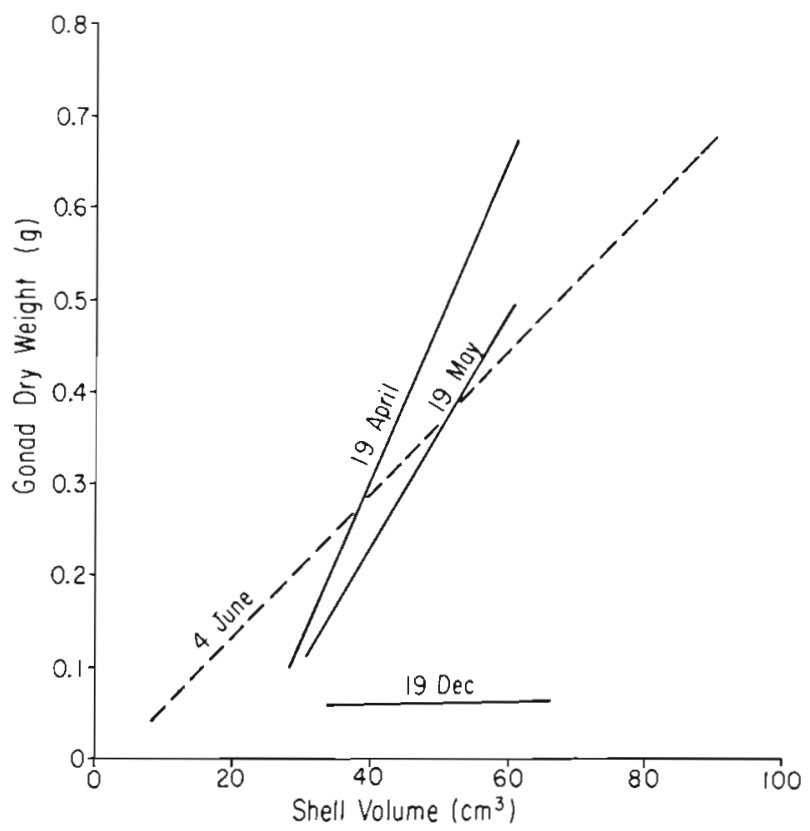

Fig. 2. Mercenaria mercenaria. Gonadal mass as a function of shell size. Data (solid lines) come from Peterson \& Fegley (1986) and represent the months of highest (Apr, May) and lowest (Dec) gonadal mass at Back Sound in 1982: Apr $\left(r^{2}=0.52 ; \quad n=22 ; \quad p<0.01\right) ; \quad$ May $\left(r^{2}=0.53 ; \quad n=19 ;\right.$ $\mathrm{p}<0.01) ; \operatorname{Dec}\left(\mathrm{r}^{2}=0.00 ; \mathrm{n}=19 ; \mathrm{p}>>0.05\right)$. Dashed line represents Johnson Creek data from the current study. Each line extends only over the range of shell volumes actually used in the analysis

sizes and slowing toward isometric growth at larger sizes. Nevertheless, the large differences between the 2 previous collections (Peterson 1983) of M. mercenaria and the new one described here in their degree of deviation from isometric growth of gonadal mass cannot be explained adequately by differences in sizefrequency distributions (Table 2). The 1980 and 1981 collections from Back Sound continue to suggest that growth in fecundity occurs at a faster rate than growth in shell volume. In contrast, the new collection implies the existence of isometric growth of gonadal mass in 1982 for Johnson Creek clams. Although all 3 collections were taken at approximately the same time of year, they were taken in different years, at 2 different sites, and conceivably at different stages in the reproductive cyle. The high degree of similarity in the power curves fit to the 2 Back Sound collections, however, suggests that differences between sites are more important than differences among years. If true, emergent theory on the allometry of fecundity would have to incorporate the intriguing possibility of substantial local variation within a species. Despite local sitespecific differences in the allometry of reproductive output, both sites are consistent in demonstrating that gamete production in $M$. mercenaria continues into old age as a simple function of shell size. 
Acknowledgements. I thank B. F. Beal, P. B. Duncan, S. R. Fegley, S. Smith, and H. C. Summerson for the field collection and K. Bowers for clam dissections. The manuscript has been improved through suggestions by S. R. Fegley, W. Sutherland, O. Vahl, and M.C. Watzin. Support came from the Office of Sea Grant, NOAA, U.S. Dept. of Commerce under Grant \#NA81AA-D-00026, North Carolina Department of Administration.

\section{LITERATURE CITED}

Hallam, A. (1967). The interpretation of size-frequency distributions in molluscan death assemblages. Paleontology 10: $25-42$

Hughes, R. N., Roberts, D. J. (1980). Reproductive effort in winkles (Littorina spp.) with contrasted methods of reproduction. Oecologia (Berl.) 47: 130-136

Kleinbaum, D. G., Kupper, L. L. (1978). Applied regression analysis and other multivariable methods. Duxbury Press, Boston, Massachusetts

Peterson, C. H. (1983). A concept of quantitative reproductive senility: application to the hard clam, Mercenaria mercenaria (L.)? Oecologia (Berl.) 58: 164-168

Peterson, C. H., Fegley, S. R. (1986). Recognition of seasonal reallocation of energy into reproductive effort. Biol. Bull. mar biol. Lab., Woods Hole (in press)

Peterson, C. H., Duncan, P. B., Summerson, H. C., Safrit. G. W., Jr. (1983). A mark-recapture test of annual periodicity of internal growth band deposition in shells of hard clams, Mercenaria mercenaria, from a population along the southeastern United States. Fish. Bull. U.S. 81: $765-779$

Porter, H. J. (1964). Seasonal gonadal changes of adult clams, Mercenaria mercenaria (L.), in North Carolina. Proc. Nat. Shellfish. Assoc. 55: 35-52

Rhoads, D. C., Lutz, R. A. (1980). Skeletal growth of aquatic organisms. Plenum, New York

Spight, T. M., Emlen, J. (1976). Clutch sizes of two marine snails with a changing food supply. Ecology 57 : $1162-1178$

Vahl, O. (1981). Age-specific residual reproductive value and reproductive effort in the Iceland scallop, Chlamys islandica (O. F. Müller). Oecologia (Berl.) 51: 53-56

Vahl, O. (1985). Size-specific reproductive effort in Chlamys islandica (O. F. Müller): reproductive senility or stabilizing selection. In: Gibbs, P. E. (ed.) Proc. 19th Europ. Mar. Biol. Symp. (16-21 September 1984). Cambridge University Press, Cambridge

Accepted for printing on November 18, 1985 